\title{
Medicolegal
}

\section{The Gee case: first expert witness}

\author{
CLARE DYER
}

After a three day adjournment the trial of Dr Sidney Gee's libel action against the $\mathrm{BBC}$ moved into a new phase as the court began hearing the evidence of Dr Gerald Swyer, the first of the expert witnesses to be called on Dr Gee's behalf. A consultant endocrinologist in the department of obstetrics and gynaecology of University College Hospital and Medical School from 1951 to 1978, Dr Swyer told the court that he was one of two researchers who carried out what he believed was the first double-blind trial of dried thyroid and dexamphetamine, the results of which were published in Clinical Science in 1950. At that time, he said, use of dried thyroid and amphetamines as adjuncts to dieting in the control of obesity was fairly widespread.

He and his coauthor had found that the administration of $5 \mathrm{mg}$ of dexamphetamine three times a day produced a statistically significant increase in the rate of weight loss, he said. Although there was a greater weight loss when dried thyroid in a daily dose of $90 \mathrm{mg}$ was given, the difference between that and the weight loss with placebo was not statistically significant. With dexamphetamine plus dried thyroid the weight loss was again greater than that with dexamphetamine alone, but the difference was not statistically significant. He said no adverse effects had been encountered in the patients. Subsequent trials, particularly in the United States, had generally confirmed those conclusions but showed that the administration of thyroid hormone could assist weight loss after the use of calorie controlled diets.

Dr Swyer said that he disagreed with the view, commonly held in Britain, that, on the one hand, dexamphetamine could be a perilous drug and, on the other, no person with a normal thyroid function ought to be given thyroid hormone treatment. In the United States the use of both thyroid and anorectic drugs had been widespread and still continued. Experimental activity using thyroid hormone treatment in conjunction with low calorie diets still went on in Britain, he added, and there had been recently published papersfor example, from Professor Mills's department in Cambridge.

Dr Swyer said that he would consider a charge that Dr Gee had endangered the lives of his obese patients by the drug therapy aspect of his treatment to be wholly unjustified. He found the allegation that Dr Gee's treatment had made Mrs Day thyrotoxic unconvincing. Michael Beloff QC, leading counsel for Dr Gee, took Dr Swyer through Mrs Day's alleged symptoms. Dr Swyer concluded that the symptoms were not inconsistent with an anxiety state.

Mr Beloff referred Dr Swyer to Mrs Day's thyroid test, taken within a week after she came off the thyroid extract. Dr Swyer said that the thyroxine concentration of $156 \mathrm{nmol} / \mathrm{l}$ was within the upper part of the normal range, bearing in mind that Mrs Day had been having thyroid treatment. The total thyroxine figure of $115 \mathrm{nmol} / \mathrm{l}$ six days later was a wholly normal figure and would imply that the dried thyroid treatment was no longer having any effect on the blood test.

With regard to Mrs Day's raised pulse rates, Dr Swyer said the fact that there were high readings several months after treatment

London NW1

CLARE DYER, BA, BLS, solicitor and legal journalist had stopped led to the conclusion that there was a cause other than the treatment. He said he would come back to an anxiety state as being the most likely cause, no doubt made worse from time to time by increased stresses in her environment.

Moving on to the case of Mrs White, Dr Swyer said that he had not seen any convincing evidence that hyperthyroidism had played any part in her condition. Intermittent palpitations pointed possibly more directly to a condition affecting the heart. On the evidence, he said, he did not think that the charge that Dr Gee's treatment had caused or contributed to Mrs White's death was made out, on the balance of probabilities.

Asked whether it was more probable than not that Mrs Falconer had been made hyperthyroid by Dr Gee's treatment, Dr Swyer replied that the evidence was by no means satisfying. Mr Beloff asked him to look at Mrs Falconer's "controversial" thyroid test, carried out on the Thursday preceding her death. Dr Swyer said that the T4 value given-which he took to be the total serum thyroxine-was $146 \mathrm{nmol} / \mathrm{l}$, within the upper range of normal. But the $\mathrm{T} 3$, if it meant the serum $\mathrm{T} 3$ concentration, was impossibly high. He therefore assumed, he continued, that it was shorthand for T3 resin uptake. The figures were precisely what one would expect to find in a woman taking oral contraceptives, when a relative raised total thyroxine and a decreased T3 resin uptake would be characteristic.

Dr Swyer added that if his interpretation of the T3 figure was right then the figure of 200 for the free thyroxine index was wrong. Doing the calculations correctly would give a figure of 106, pretty close to the normal range.

Looking at Mrs Falconer's postmortem report, Dr Swyer said that there was nothing that pointed directly to her having been made thyrotoxic by Dr Gee's treatment. The weight of her thyroid gland was on the low side, which could indicate that the gland had been suppressed, but that could have been caused by the administration of exogenous thyroid hormone. From the description of the cardiovascular system he inferred that she had significant coronary atheromatous disease, which had nothing to do with Dr Gee's treatment but might have had to do with her smoking and being on the pill.

Moving on to the effects of Dr Gee's treatment in pregnancy, Dr Swyer said there was no evidence that thyroid hormone, provided it was not in excess, did any harm to a pregnant woman or her fetus. There was no convincing epidemiological evidence of increased incidence of congenital malformations in babies born to mothers who were taking amphetamine.

Cross examined by Andrew Rankin QC, leading counsel for the BBC, Dr Swyer said that the 1950 article he had referred to earlier was the only original article he had written on obesity. In the endocrine clinic he ran before he retired, he said, he had seen at least one new obese patient at each clinic. It was always his practice to start off the medical history by asking about the family history, particularly of hypertension, cardiovascular problems, and diabetes. Every patient at each attendance had a urine test.

Dr Swyer said that he had stopped giving thyroid hormones for obesity probably around 1965 . Occasionally he would use thyroxine for patients whose thyroid function when measured was in the lower part of the normal range. Such patients would be started on a low 
dose that was increased stepwise and advised to report back if they had palpitations, were feeling nervy or jittery, or were sweating excessively.

Mr Rankin put it to Dr Swyer that with thyroid hormones the practitioner must be on the lookout for an "overdose situation." Dr Swyer agreed. He also agreed with Mr Rankin's suggestion that overdosing might be dangerous if maintained for sufficiently long, and that if a therapist decided that some patients needed the thyroid hormone crutch he had to be selective because it would not apply to every patient to start with. Dr Swyer said that the degree of excess needed to produce signs of thyrotoxicosis varied considerably in different people, and that hyperthyroidism, if sufficiently severe and long maintained, was life threatening.

Mr Rankin showed Dr Swyer graphs of the heart rate of a consultant physician before and after a 30 day course of Dr Gee's thyroid extract tablets, $250 \mathrm{mg}$ a day. The heart rate had been monitored for 24 hours, he said. Dr Swyer agreed that the difference in heart rate was a large one, and the difference during sleep was likely to be significant. Looking at a graph that showed the consultant's triiodothyronine concentration and heart rate together, Dr Swyer agreed that it would appear that the consultant had been rendered thyrotoxic. He agreed that if this experiment was valid then some of Dr Gee's patients might well have been rendered thyrotoxic, but he said he assumed that these would have been the patients in whom Dr Gee would have stopped the treatment.

Mr Rankin put it to Dr Swyer that if Mrs Day's free thyroxine level had been 28 and was now 21 , that could not be explained on the basis of an anxiety state. Dr Swyer agreed that it could not be wholly so explained; the two figures were consistent with the view that she was at one time thyrotoxic.

Turning to Mrs Falconer's thyroid function test, Mr Rankin pointed out that Dr Swyer had fallen into error in assuming that the T3 referred to in the report was T3 resin uptake. Dr Swyer agreed; he now understood, he said, that it was a Thyopac- 3 test, and he had been misled by the laboratory shorthand. However, the figures were internally inconsistent, given the fact that she was taking oral contraceptives, and he would have grave doubts about the validity of any conclusions drawn from them. But if the figures were, despite his criticism, correct he agreed that they would be compatible with a thyrotoxic state.

Addressing the three leading counsel in the case, Lord Justice Croom-Johnson pointed out that the trial had already taken up more than 40 days. He added: "By the time it has come to an end the amount of costs which would be at risk for somebody will be of an enormous amount, and I cannot help reflecting that the first four defendants [the BBC, Esther Rantzen, That's Life assistant presenter, Gavin Campbell, and the programme's editor, Gordon Watts] are being funded by public money."

His Lordship said that he wanted to make a start on limiting, as far as possible, the matters in dispute. He questioned the defendants' counsel as to how far Dr Gee's allegations about the meaning of the words used were admitted. Mr Rankin agreed with the judge's summary of what the BBC was saying: that Dr Gee had put Mrs Day's life at risk, had prescribed dangerous drugs, and was guilty of negligence and therefore unfit to remain in practice. He agreed with the judge's wording of the BBC's view on Dr Gee's thyroid treatment-."A doctor could honestly hold the view that thyroid extract could be used to treat obesity, but he could not properly go on to prescribe $250 \mathrm{mg}$ per day, however honestly his view was held"-with the addition of the words "in the circumstances in which Dr Gee operated"-in other words, his routine examination and monitoring.

Mr Beloff supported Mr Rankin's submission that it would be appropriate to have argument on the meaning to be attributed to the defamatory words at the earliest convenient time. He added that he had no doubt that the trial would exceed the postwar record of 101 days. "One really feels," he concluded, "one is not even halfway up Everest and barely at base camp."

\section{Medicine and the Media}

\begin{abstract}
A BUNCH OF enthusiasts sets up a "hospital shop," encourages the locals to come forward with relics and photographs of the town hospital, and then records their memories on video. All that must be good for community involvement in local health care. This is just what the Television History Workshop Group did in Stoke last year, and the profile that the collective memory produced of Stoke City General Hospital can be seen in six programmes (C4, Sunday $1015 \mathrm{pm}$, first one 10 February). It will surely be the most extensive exposure ever given to a single hospital by the British media.

What we get is the human face of the hospital, and many of the interviews make sobering viewing. Up to the advent of the National Health Service in 1948 the City General had been Stoke's poor law hospital; and retired technicians and laundresses recall with indignation the terrible stigma attached to being a patient, and even a worker, at the "pauper hospital," where conditions remained harsh and even primitive. We hear of pauper inmates who never got out but spent the rest of their lives scrubbing the floors. It is shocking to be reminded that healing and what amounted to punishment were united in one institution within living memory. No wonder that many of the elderly staff interviewed-warm, dedicated people, all of them-express their fears for the future of the NHS.

And yet the series lets a golden opportunity go begging. It's not actually good television. The producers are obviously keen on "authenticity"; footage of staff reminiscing into the camera, broken
\end{abstract}

up by shots of routine work in the City General today (washing up, stoking boilers, filing records) and by pretty didactic caption quotes ("it's not a romantic life")-_some of them misspelt! One can respect the aim: this is people's history, let the people tell it their way, let us see the worker's eye view of the hospital. But it comes across as disjointed, jumping from past to present, from snippet to snippet. A tactful linking script, a knowledgeable presenter, some probing interview questions would have made all the difference. The production team evidently believes that things should speak for themselves. But that's a myth (remember the editing room), and it leads to irritating viewing.

All this means one eyed history. Oral history is vital, but it needs setting within a wider framework. We need nurses' tales about matron, but we also need someone with skill to take a wider view and fill us in on what a pauper hospital really was, how it ran, who controlled it, who got admitted, how good or bad the medical treatment really was. But here we have history without historians, and no one has gone and looked at the hospital's records, explained its finances, or probed its prescription books and diet sheets. We get no dialogue between popular memory and official record. Maybe that was thought too elitist.

Not surprisingly, the result is a bizarre imbalance. The collage of interviews with porters and domestics certainly shows the hospital as a place of work and workers. But what of it as a place of sickness and medicine? We see too little of that. Media stereotypes of hospitals probably give too much prominence to doctors. But here is 